\title{
Tod der Płocker Bischöfe im Soldauer Konzentrationslager
}

\author{
Death of the Płock bishops in the Nazi camp in Działdowo
}

\begin{abstract}
In September 1939 in Działdowo the Nazis established a transit camp for the war prisoners of the Polish September Campaign of 1939 in the former barracks of the 32 infantry regiment on Grunwaldzka Street. At the turn of 1939 and 1940 the police and the SS authorities in Königsberg transformed the Działdowo camp into the transit camp „Durchgangslager“. Priests imprisoned in the Działdowo camp from autumn 1939 to autumn 1941 constituted a special group of political prisoners. The archbishop Antoni Julian Nowowiejski and the bishop Leon Wetmański, Płock bishop suffragan, were brought to the Działdowo camp in 1941. The Płock bishops quickly became spiritual guides and the support for the prisoners in difficult moments of camp life. In order to prevent their contacts with the prisoners, the bishops were put in a separate cell number 12. They were subjected to different kinds of moral and physical torture, including the attempt to profane the cross. Difficult living conditions in the camp soon led to the death of the Płock priests: the archbishop Antoni Julian Nowowiejski died on 28 May 1941 and the bishop Leon Wetmański died on 10 October 1941. Apart from them, 47 priests and 1 seminarian lost their lives in the Działdowo camp in 1939-1945.
\end{abstract}

\section{Keywords}

Płock bishops, Nazi camp, Działdowo, Soldau camp, Nowowiejski, Wetmański, martyrdom.

Im September 1939 wurde von den Nazis in der ehemaligen Kaserne des 32. Infanterieregiments in der Grunwaldzka-Straße ein Übergangslager für die im Polenfeldzug gefangenen Soldaten errichtet. Der Lagerkomplex, der vier zweistöckige einfache Gebäude umfasste, nahm eine Fläche von ca. 8 ha ein. Die ersten Lagerinsassen waren Soldaten der Festungsbesatzung Modlin. Sie wurden vor Ort nach Dienstrang getrennt und nach einiger Zeit in bestimmte 
114 Volume 3 (2013) Number 2, p. 113-121

Offiziers- bzw. Stammlager eingeliefert. Das Soldauer Lager wurde einer deutschen Kommandantur unterstellt. Die Kriegsgefangenen mussten unter freiem Himmel hausen und wurden von den Bewohnern der Gegend um Soldau mit Nahrungsmitteln versorgt. Die extrem schwierigen Bedingungen waren Ursachen für den Tod vieler polnischer Kriegsgefangener.

Im Winter 1939/40 wurde das Soldauer Lager vom SS- und Polizeiamt Königsberg in ein sog. „Durchgangslager“ umgewandelt. Zum ersten Lagerkommandanten wurde Hauptsturmführer Hans Krause und zu seinem Vertreter Willi Miller, ein Volksdeutscher und ehemaliger Kapitän der polnischer Armee, ernannt. Andere Soldauer Volksdeutsche wurden zu Mitarbeitern des Kommandanten Krause: Antoni Krupski, Paul Skuza, Wilhelm Lukasz, Gustaw Swierman, Kurt Lenart, Fryc Belke, Fryc Dworak, Otto Szmaglowski, Gebrüder Plazan und Koszowitz. In Iłowo, Mławka und Nosarzewo wurden Filialen des Soldauer Lagers errichtet. Bald wurde das Lager zum Folter- und Vernichtungsort für polnische Patrioten ${ }^{1}$.

Soldauer Häftlinge wurden individuell oder in Gruppen in den Wäldern bei Komorniki, Białuty, Bursz, in dem sog. Lasek Żwirski bei Soldau und auf dem jüdischen Friedhof in Soldau durch Erschießung hingerichtet, im Einzelfall aber exekutierte man sie auch auf dem Lagergelände: auf dem zentralen Platz oder im Keller. Diese Handlungen wurden streng geheimgehalten und durch vorgetäuschte Aussiedlungen verdeckt.

Die Häftlinge wurden mit beplanten Lkws transportiert. Es wurden schon vorher 2 Metertiefe, 8 Meter lange und6 Meter breite Gruben ausgehoben. Vorden Erschießungen wurden sowohl die Gruben als auch die vorbeifahrenden Wagen von den Anwohnern gesehen, die dann auch Schüsse des Maschinengewehrs hörten. In dem 1947 in Soldau von der Kreiskommission zur Ermittlung von NS-Verbrechen in Warschau durchgeführten Ermittlungsverfahren und bei der in Anwesenheit von Vertretern des Polnischen Roten Kreuzes vollzogenen Exhumierung wurden diese Verbrechen durch mehrere Berichte bestätigt ${ }^{2}$.

Eine spezielle Häftlingsgruppe bildeten im Soldauer Lager Priester, die vom Herbst 1939 bis zum Herbst 1941 im Lager gefangen gehalten wurden. 1941

1 Vgl. Z. Dudzińska, Obozy hitlerowskie na ziemiach polskich 1939-1945. Informator encyklopedyczny, Warszawa 1979, S. 164-165; H. Piwoński, Życie religijne w hitlerowskim obozie w Działdowie w latach 1939-1945, (Ms.), S. 12-13.

2 Vgl. H. Piwoński, Życie religijne w hitlerowskim obozie w Działdowie w latach 1939-1945, (Ms.), S. 17. 
wurden Erzbischof Antoni Julian Nowowiejski, Bischof von Płock ${ }^{3}$, und Bischof Leon Wetmański, Suffraganbischof von Płock ${ }^{4}$, ins Lager eingeliefert. Von den anderen Häftlingen streng getrennt wurden sie in die Zelle Nr. 12 eingesperrt und besonderen Schikanen ausgesetzt. Erzbischof A.J. Nowowiejski wurde auf vielfältige Weise geistigen und körperlichen Misshandlungen, darunter auch der versuchten Kreuzschändung, unterzogen. Er ist vermutlich am 28. Mai 1941 im Alter von 83 Jahren, nach 60 Jahren Dienst als Priester, davon 33 Jahre als Bischof, gestorben. Als Todesursache nannten die Nationalsozialisten Altersschwäche. Bis heute bleibt sein Beerdigungsort unbekannt. Bekannt sind zwar die Namen von zwei Juden (Pużycki und Sakwa), die den Leichnam des verstorbenen Bischofs aus dem Lager hinausbrachten, beide wurden jedoch bei der Auflösung des KZ erschossen. In der seit 1945 erstellten Dokumentation über das Martyrium der Płocker Bischöfe wird auf einen Wald in Malinowo auf dem Berg Góra Komornicka oder Białuty als vermutlichen Beerdigungsort von Bischof A. J. Nowowiejski hingewiesen.

In einer offiziellen Nachricht der deutschen Behörde über den Tod von Bischof L. Wetmański wurde der 10. Oktober 1941 genannt. Als Todesursache wurden in dieser Benachrichtigung der Darmkatarrh und allgemeine

3 Erzbischof Antoni Julian Nowowiejski ist am 11.02.1858 geboren. Am 10.07.1881 hat er seine Priesterweihe aus den Händen des Bischofs Aleksander Gintowt erhalten. Im Juni 1882 wurde er zum Professor des Priesterseminars in Płock ernannt, wo er Latein, Liturgie und Moraltheologie unterrichtete. 1882-1883 war er als Vikar in der Pfarrei Sankt Bartolomäus und Rektor der postreformatorischen Kirche in Płock tätig. 1883 wurde er vom Bischof Kacper Borowski zum Vizerektor des Priesterseminars ernannt und bekleidete diese Funktion bis 1901. Zu dieser Zeit erwies er sich nicht nur als konsequenter Erzieher, sondern vor allem als ausgezeichneter Professor, exzellenter Kenner und Liebhaber der Liturgie. Sein tiefes Interesse an der Liturgie veranlasste Bischof Kossowski, ihn zum Zeremoniar der Kathedralkirche zu ernennen. Mittlerweile stellte er seine ersten Veröffentlichungen aus dem Bereich der Liturgik fertig. Ein Jahr zuvor wurde er mit einer geheimen Mission beauftragt, in Rom eine spezielle Facultates für den durch die zaristische Regierung verfolgten Diözesanadministrator Bischof Kossowski zu erlangen. 1901-1908 war er Rektor des Priesterseminars. 1908 wurde er von Papst Pius X. zum Bischof von Płock ernannt. Am 28. 02.1940 wurde er von Deutschen interniert und zunächst nach Słupno und am 07.03.1941 ins Durchgangslager Soldau eingeliefert, wo er vermutlich am 28.05.1941 den Märtyrertod starb.

4 Bischof Leon Wetmański, geb. am 10.04.1886 hat seine Priesterweihe aus den Händen des Bischofs A. J. Nowowiejski erhalten. 1912-1918 studierte an der Geistlichen Akademie St. Petersburg. Seit 1918 war er geistlicher Vater im Priesterseminar in Płock. Am 19.12.1927 wurde er zum Weihbischof der Diözese Płock ernannt. Am 07.03.1941 wurde er mit dem Erzbischof in das Konzentrationslager Soldau eingeliefert, wo er vermutlich am 19.10.1941 den Märtyrertod starb. 
körperliche Erschöpfung angegeben. Von 1939 bis 1945 wurden im Soldauer Lager insgesamt zwei Bischöfe, 47 Priester und ein Kleriker ermordet ${ }^{5}$.

„Wir sollten uns an den Märtyrern der ersten christlichen Jahrhunderte Beispiel nehmen, die in den schwierigsten Momenten sich selbst vergaßen und nur danach fragten, was sie für Gott tun könnten“. Diese Worte schrieb Erzbischof A.J. Nowowiejski in seinem Hirtenbrief zum Advent 1939. Sie waren zwar an Gläubige in seiner Diözese im ersten Advent des grausamen Krieges gerichtet, bald haben sie sich jedoch in seinem Leben bewahrheitet. Nach fast einjähriger Internierung in Słupno bei Płock umstellten die Gendarmen gegen 1 Uhr in der Nacht vom 6. auf den 7. März das Schulgebäude, in dem die Bischöfe von Płock gefangen gehalten wurden, und forderten sie auf, das Gebäude sofort $\mathrm{zu}$ verlassen. Sie wurden zunächst in das Magistratsgebäude in Płock und am nächsten Tag, dem 8. März, hungrig, durchfroren und eingeschüchtert in das Übergangslager Soldau eingeliefert, wo sie gegen Mittag eintrafen. Nach einer genauen Leibesvisitation wurden Erzbischof Nowowiejski und Bischof Wetmański in die Zelle Nr. 12 eingesperrt, wo äußerst schwere Bedingungen herrschten. Es war kalt und es gab keine Betten, geschweige denn einen Stuhl und einen Tisch. Als Bettlager sollte verstreutes, altes, gebrochenes Stroh voll Würmer dienen. Der Erzbischof suchte für sich einen Platz in der Ecke aus, aber vor Kälte und wegen der Insekten konnte er in seiner ersten Nacht im Lager kein Auge zudrücken. Außerdem quälte ihn der Hunger, weil er bereits seit zwei Tagen nichts gegessen hat. Auch das Wasser war knapp, sodass sie ihren Durst kaum stillen konnten und das Waschen gar nicht möglich war.

Mit anderen Häftlingen, darunter auch Priestern, in einer Zelle dicht zusammengedrängt litten die Płocker Bischöfe auch unter mangelnder Bewegung und frischer Luft. Deutsche Häscher dachten sich mittlerweile immer wieder neue, ausgeklügelte Foltermethoden aus. So mussten sie z.B. den ganzen Tag regungslos auf dem Betonboden mit dem Rücken an die Wand gelehnt sitzen oder mit aufgehobenen Händen und dem Gesicht zur Wand stehen. Besonders für den über 83jährigen Erzbischof bedeutete das eine kaum erträgliche Anstrengung. Sie haben jedoch ihr Leiden tapfer über sich ergehen lassen und ihre geradlinige heitere Einstellung behalten. Ihre Haltung provozierte aber die Vollstrecker des NS-Regimes zu neuen Hassausbrüchen, weil sie ihren Stolz und ihre Priesterehre, die die Bischöfe trotz allem

Vgl. H. Piwoński, Życie religijne w hitlerowskim obozie w Działdowie w latach 1939-1945 (mps), S. 19-20. 
bewahrt hatten, nicht ausstehen konnten. Deswegen wandten sie verschiedene Erniedrigungsmethoden an. Häufiges Aufsuchen der Zelle Nr. 12 durch die SS-Männer führte zu körperlicher Entkräftung beider Häftlinge. Gefoltert und geschlagen mussten sie noch Gymnastikübungen machen, die ihre Kraft überstiegen, z.B. tausendmal Stürzen nach vorne üben. Als Folge solcher schmerzhaften Erfahrungen trat besonders bei Erzbischof Nowowiejski bald die Erschöpfung ein. Die schlimmsten Punkte des Tagesprogramms waren jedoch der Morgen- und der Nachmittagsgang auf die Latrine, die immer von „körperlichen Übungen“ begleitet wurden, an denen beide Bischöfe täglich teilnehmen mussten. Damit war der Erzbischof völlig überfordert: von Bischof Wetmański oder von den Priestern Zaleski und Caban gestützt blieb er immer hinter der Gruppe zurück. Die Priester bekamen für die ihrem Hirten erwiesene Hilfe desto häufiger und mehr Peitschenschläge. Eine unentbehrliche „Attraktion“ des Ganges waren immer wieder gerufene Kommandos: „Fall!“ und „Steh auf!“ sowie Fußtritte, die den im Schlamm liegenden Häftlingen reichlich versetzt wurden. Einer der SS-Männer demütigte den liegenden Bischof Wetmański, indem er ihn mit seinem Stiefel im Schlamm umwälzte und auf ihm herum trampelte. Ein anderes Mal rissen sie dem Bischof unter Schlägen, Schreien und Fußtritten seine ausgediente Wintermütze vom Kopf, tauchten sie im Schlamm ein und setzten sie ihm wieder auf.

Die Kapuzinerschwestern aus Przasnysz, die die Gräuel des Konzentrationslagers in Soldau überlebt haben, erinnerten sich an die grausamen körperlichen Übungen, die Gottesdiener und andere Priester ausführen mussten: „Es war kaum erträglich, zweimal am Tag diesem schmerzhaften und ausgesprochen mörderischen Gang der Priester auf die Toilette zuzusehen. Fußtritte, Schläge, Misshandlungen waren dann an der Tagesordnung und die Gymnastik, zu der die Häftlinge gezwungen wurden, musste sich Teufel selber ausgedacht haben, so anstrengend und herabwürdigend war sie“. Kein Wunder, dass die Płocker Bischöfe von diesen Spaziergängen häufig mit Wunden im Gesicht, blutunterlaufenen Lippen und blau geschlagenen Augen zurückkamen.

Besonders brutal wurde der Erzbischof am Karfreitag, 11. April 1941, geschlagen. Deutsche Schergen wollten ihm wohl einen Teil dieses Leidens zuteilwerden lassen, das Christus auf Seinem Weg zum Kalvarienberg erfahren hat. Er dachte oft über Christi Leiden nach, betrachtete es und wollte Christus auf seinem Weg nachahmen. Von einem jungen, eifrigen und hasserfüllten Deutschen hart geschlagen fiel Erzbischof Nowowiejski zu Boden und versuchte 
instinktiv mit den Händen seinen Kopf zu schützen. Sein Kreuz war aber schwer - der Erzbischof fiel hin und wie Jesus stand er dank der Hilfe des guten Simon in Person von Bischof Wetmiński bald auf.

Sein Verhalten und seine ethische Haltung in diesen extrem schwierigen Situationen machten ihn zum geistigen Führer aller Häftlinge, an dem sie in den härtesten Momenten des Lageralltags Halt finden konnten. Diese geistige Ausgewogenheit, die man unabhängig von Lebensumständen erreicht, wird nur denjenigen zuteil, die sich dank ihres inbrünstigen Glaubens wie auf einem festen Fundament zum höchsten Gipfel der Heiligkeit erheben. Ihr Gebet erhellte wie wertvollstes Juwel die Düsternis des Lagerdaseins. Der Erzbischof betete unaufhörlich, forderte auch andere Häftlinge zum Gebet auf und bat dabei immer Bischof Wetmański, das Gebet zu führen. Jeden Tag beteten sie halblaut oder flüsternd den Rosenkranz, der sie alle stärkte und ermunterte - ganz besonders als sie die schmerzensreichen Geheimnisse betrachteten. Da kamen die Gedanken an das Gebet im Garten Gethsemane, an den Kalvarienberg und den Kreuzweg hoch und alles, was Jesus erlitten hat, wurde zur Realität. Bischof Wetmański ermunterte sie mit warmen und erbauenden Worten zur Ausdauer und wies darauf hin, dass der Heilsweg über Leiden führt. Derjenige, der vorher so oft über das Martyrium sprach, ging jetzt selber den Märtyrerweg. Er sagte: „Auf die Gnade des Martyriums muss man sich lebenslang vorbereiten, sonst kann die Seele nicht genug Ausdauer aufbringen, wenn es tatsächlich naht ${ }^{\text {“6 }}$. Der Märtyrergedanke wurde noch vor dem Krieg immer wieder während der Konferenzen von ihm ausgesprochen. Er reifte unerkannt in seiner Seele. Als er im April 1932 sein Testament anfertigte, schrieb er: „Würdest Du mir, barmherziger und guter Gott, die Gnade geben, die Märtyrertod genannt wird, so nimm ihn für meine Sünden hin und für diejenigen, die mir den Tod antun werden, damit auch sie Dich, guter und barmherziger Gott, von ganzem Herzen lieben“7. Deswegen schrieben die Kapuzinerschwestern - Zeuginnen des Lagerdaseins in Soldau, als sie sich an diese Zeit, den Bischof und andere Häftlinge erinnerten: „In Soldau litten alle, waren sie aber alle Märtyrer? Das weiß nur Gott allein... Wer jedoch sein Leben lang nur auf Gott schaute und im Leiden einen großen, tiefen Sinn erblickte, dem schenkt Gott wohl die Märtyrerpalme?“.

6 Aus dem Bericht der Kapuzinerschwestern aus Przasnysz über Bischof L. Wetmański, den sie an W. Jezusek im Februar 1948 geschickt haben, „Studia Płockie“ 18 (1990), S. 273.

7 Testament vom 14.04.1932 veröffentlicht in: W. Górski, Będziecie moimi świadkami, Płock 1992, S. 20. 
Unter diesen Umständen reifte schnell der Märtyrergedanke. Weder Erzbischof Nowowiejski noch Bischof Wetmański rühmten sich ihres Leidens. In den Tiefen ihrer Priesterherzen betrachteten sie intensiv das Leiden Christi, ihres Meisters, dem sie sich völlig hingaben, und verbanden damit ihr Leiden. Als nach einer Misshandlung Bischof Wetmański mit dem blutbeschmierten Gesicht den Ordensschwestern begegnete, segnete er sie und wich dann rasch in eine unsichtbare Ecke seiner Zelle zurück.

Als außergewöhnliche, reife und durch den Glauben belebte Persönlichkeiten erzeugten Erzbischof Nowowiejski und Bischof Wetmański im Konzentrationslager die Atmosphäre tiefer Religiosität. Die Gottesdiener hatten immer Mitleid mit gefolterten und misshandelten Mithäftlingen. Sie waren sich dessen bewusst, dass sie für diese unmenschlich gequälten Menschen einzige Stütze und einziger Trost sind. Sie stärkten oft durch aufmunternde Worte ihren Geist und erteilten ihnen den Hirtensegen. Kurz vor seinem Tod bestätigte das ein anderer Gefangener aus Soldau, der Schmied Wilhelm Sowa: „Die Bischofe trösteten die Häftlinge, flößten ihnen Mut ein und waren bei den Häftlingen beliebt ${ }^{\star 68}$. Nicht bei allen weckte ihre Haltung Freundlichkeit und Vertrauen. Verständlicherweise rief sie bei den KZ-Aufsehern Abneigung und Hass hervor. Die Folterknechte wetteiferten darin, den Bischöfen psychische und körperliche Schmerzen zuzufügen. Das Leiden stärkte sie aber nur und veredelte ihren Geist.

Nach Zeugenberichten wurden sie kurz vor ihrem Tod auf eine ganz besondere Probe gestellt - sie wurden aufgefordert das Kreuz Christi zu schänden. Von diesem Ereignis berichtete der bereits zitierte Zeuge Wilhelm Sowa, geboren und wohnhaft in Brodów, der bis Mitte August 1941 mit Priestern und Bischöfen im Konzentrationslager gefangen gehalten wurde. Sein Bericht wurde durch die Aussage seiner Schwester bekannt, der er von seinen Lagererfahrungen erzählte. „Wilhelm Sowa arbeitete als Häftling in der Lagerschmiede, die sich im Keller des Gebäudes befand, in dem die Płocker Bischöfe gefangen gehalten wurden. Gegenüber seinem Arbeitsraum auf der anderen Seite des Korridors war der sogenannte „Bearbeitungsraum“. Der Schmied hörte oft durch die Tür, dass Häftlinge dorthin zum Foltern geführt wurden. Manchmal weigerten sie sich in den Keller hinunterzusteigen, weil

\footnotetext{
8 Aus dem Bericht von Helena Falk, Schwester von Wilhelm Sowa, in: W. Jezusek, Męczeński koniec arcybiskupa Antoniego Juliana Nowowiejskiego, biskupa plockiego (1858-1941), „Miesięcznik Pasterski Płock“(1947), S. 120 f.
} 


\section{The Person and the Challenges \\ 120

sie wussten, was ihnen bevorsteht, dann wurden sie auf der Treppe erschossen. Als er einmal in der Schmiede arbeitete, wurden die beiden Bischöfe in den „Bearbeitungsraum“ geführt. Er hörte, wie sie getreten und misshandelt wurden, so dass sie ,wie Mäuse wimmerten“. Der Schmied konnte vor Aufregung nicht arbeiten und schaute zur Tür hinaus, obwohl er wusste, dass ihm dafür der Tod droht. Er wurde beim Hinausschauen vom Sturmführer ertappt und aufgefordert, in den „Bearbeitungsraum“ hineinzugehen. Dort standen die Bischöfe an der Wand und er sollte ihnen zeigen, wie man aufs Kreuz spuckt und darauf herumtrampelt. Als er sich weigerte, hörte er: „Bist du auch so dumm, daran zu glauben?". Dann folterte man ihn in Anwesenheit der Bischöfe so lange mit Strom, bis er in Ohnmacht fiel. Als er wieder zu sich kam, lag er an der Wand neben dem betenden Erzbischof, der seinen schwarzen Pulli auszog und ihn dem Schmied reichte. Als der Schmied sich weigerte, ihn anzunehmen, sagte der Erzbischof: „Den kann ich nicht mehr brauchen. Wenn du mit Gottes Hilfe nach Hause zurückkommst, kannst du ihn als Andenken behalten" .

Nach der Quälerei, die der Erzbischof durchmachen musste, verließen ihn die Kräfte. Trotzdem hörte er nicht auf zu beten. Und vielleicht bat er Gott desto eifriger, ihm selbst, seinen Mithäftlingen und den Folterknechten die Sünden zu vergeben. Dadurch ahmte der Płocker Bischof Christi Leiden und Tod vollkommen nach. Der Tod ließ nicht lange auf sich warten. Das Amtsblatt des Apostolischen Stuhls Acta Apostolicae Sedis berichtete am 21. November 1941, dass der Erzbischof von Płock Antoni Julian Nowowiejski am 28. Mai 1941 gestorben ist. Einer der Mithäftlinge reagierte auf die Nachricht von seinem Tod mit den Worten: „Er starb wie ein Bischof, der sich des polnischen Namens würdig zeigte, als Märtyrer für Christus und seine Heimat. Sein Opfer und seine grenzenlose Treue reichten über das Diesseits hinaus ${ }^{\text {" } 110}$.

Sein Schicksal teilte bald auch sein treuer Mitarbeiter Bischof Leon Wetmański. Er wurde vermutlich mit anderen Häftlingen vergast, die die Typhusepidemie überlebt hatten. Nach den durch die deutsche Behörde ausgestellten Dokumenten gilt der 10. Oktober 1941 als Todesdatum.

Die beiden Bischöfe von Płock widersetzten sich mit ihrem Tod der feindlichen, grausamen Welt. Ihre heroische Haltung trug Früchte, als sie vom

\footnotetext{
9 Ebenda.

${ }^{10}$ Arcybiskup Antoni Julian Nowowiejski (1908-1941). W pięćdziesiąta rocznicę męczeńskiej śmierci, Hrsg. A. Suski, W. Góralski, T. Żebrowski, Płock 1991, S. 489.
} 
Papst Johannes Paul II. am 13. Juni 1999 in den Kreis der Seliggesprochenen der katholischen Kirche aufgenommen wurden. Die Erinnerung an sie bleibt in der Kirche und unter den Gläubigen aus Masowien lebendig.

\section{Bibliography}

Arcybiskup Antoni Julian Nowowiejski (1908-1941). W pięćdziesiątą rocznicę męczeńskiej śmierci, Hrsg. A. Suski, W. Góralski, T. Żebrowski, Płock 1991.

Dudzińska Z., Obozy hitlerowskie na ziemiach polskich 1939-1945. Informator encyklopedyczny, Warszawa 1979.

Góralski W., Będziecie moimi świadkami, Płock 1992.

Grzybowski M.M., Martyrologium duchowieństwa diecezji płockiej w latach II wojny światowej 1939-1945, Włocławek-Płock 2002.

Jezusek W., Męczeński koniec arcybiskupa Antoniego Juliana Nowowiejskiego, biskupa płockiego (1858-1941), „Miesięcznik Pasterski Płock“ (1947).

Piwoński H., Życie religijne w hitlerowskim obozie w Działdowie w latach 1939-1945 (mps).

Wojtyska H.D., Krzyż przez nich zwyciężyt, Przasnysz 2008. 